Shu-Chuan Chiang • Yu-May Lee • Mei-Hwei Chang

Tso-Ren Wang • Tsang-Ming Ko • Wuh-Liang Hwu

\title{
Glucose-6-phosphatase gene mutations in Taiwan Chinese patients with glycogen storage disease type la
}

Received: January 4, 2000 / Accepted: February 28, 2000

\begin{abstract}
Glycogen storage disease type Ia (GSD Ia) is caused by a deficiency of glucose-6-phosphatase (G6Pase) activity. Eighteen GSD Ia families were studied for G6Pase gene mutations. Thirty-two mutations were found in 36 GSD Ia chromosomes: 16 were $727 \mathrm{G} \rightarrow \mathrm{T}(44.44 \%) ; 13$ were $\mathrm{R} 83 \mathrm{H}(327 \mathrm{G} \rightarrow \mathrm{T}$; 36.11\%); 1 was $341 \mathrm{delG}$; 1 was 933insAA; and 1 was $793 \mathrm{G} \rightarrow \mathrm{T}$. The $727 \mathrm{G} \rightarrow \mathrm{T}$ and $\mathrm{R} 83 \mathrm{H}$ mutations together accounted for $80.56 \%$ (29/36) of the GSD Ia chromosomes. These two mutations were easily examined by polymerase chain reaction-based methods, and the prenatal diagnosis of a non-affected fetus was successfully made. The $727 \mathrm{G} \rightarrow \mathrm{T}$ mutation is the predominant mutation in Japanese GSD Ia patients, but is rarely seen in Western counties. The $727 \mathrm{G} \rightarrow \mathrm{T}$ mutation is also the most prevalent mutation in Taiwan Chinese, although the incidence is not as high as in Japan.
\end{abstract}

Key words Glycogen storage disease type Ia - Glucose-6phosphatase $\cdot$ Mutation $\cdot$ Chinese $\cdot$ Taiwan

\section{Introduction}

Glucose-6-phosphatase (G6Pase, E.C.3.1.3.9) is responsible for the final step of glycogenolysis - the conversion of glucose-6-phosphate to glucose (Chen and Burchell 1995; Foster et al. 1997). Deficiency of G6Pase induces glycogen storage disease type Ia (GSD Ia; von Gierke disease; MIM no. 232,200). Excessive glycogen storage is found in the

S.-C. Chiang $\cdot$ T.-R. Wang $\cdot$ T.-M. Ko $\cdot$ W.-L. Hwu

Department of Medical Genetics, College of Medicine, National Taiwan University

M.-H. Chang · T.-R. Wang · W.-L. Hwu $(\square)$

Department of Pediatrics, National Taiwan University Hospital, 7

Chung-Shan S. Rd., Taipei 100, Taiwan, R.O.C.

Tel. +886-2-2397-0800 (ext 6702); Fax +886-2-2331-4518

e-mail: hwu@ha.mc.ntu.edu.tw

Y.-M. Lee

Institute of Biological Chemistry, Academia Sinica, Taipei, Taiwan,

R.O.C. liver, kidney, and intestine of affected individuals. Human G6Pase gene catalytic unit (G6PC; GenBank U01120), located on chromosome $17 \mathrm{q} 21$, spans $12.5 \mathrm{~kb}$ and consists of five exons (Lei et al. 1993). Several common GSD Ia mutations have been identified in different ethnic groups, e.g., the R83C and Q347X mutations in Caucasians, the 130X in Hispanics, and the $727 \mathrm{G} \rightarrow \mathrm{T}$ in Japanese (Foster et al. 1997; Lei et al. 1993; Lei et al. 1994; Lei et al. 1995; ChevalierPorst et al. 1996). R83H (327 G $\rightarrow \mathrm{T})$ has been thought to be the most prevalent mutation in Chinese (Lei et al. 1995).

We previously analyzed several Taiwan Chinese GSD Ia patients, but found that the $\mathrm{R} 83 \mathrm{H}$ mutation accounted for only $25 \%$ of the chromosomes (Hwu et al. 1995). Recently, the $727 \mathrm{G} \rightarrow \mathrm{T}$ mutation was found to be prevalent in Hong Kong Chinese patients (Lam et al. 1998). In this article, we report on 18 GSD Ia families, including one fetus, who were studied for G6Pase gene mutations. We found that 727 $\mathrm{G} \rightarrow \mathrm{T}$ was the most prevalent mutation in Taiwan Chinese.

\section{Subjects and methods}

Eighteen families with GSD Ia were studied (see Table 1). The first eight patients listed in Table 1 and patient 13 have been described previously (Hwu et al. 1995; Hwu et al. 1999). All patients had typical clinical and laboratory findings, including short stature, hepatomegaly, hypoglycemia, lactic acidosis, hyperlipidemia, hyperuric acidemia, and flat glucose response to glucagon stimulation. Clinical information, including sex and age at diagnosis, is summarized in Table 1.

Genomic DNA was extracted from the peripheral blood of the patients and their parents. Chorionic villus sampling from the fetus of the mother of patient 13 was performed at 12 weeks of gestation after informed consent and permission of the ethics committee were obtained. DNA was extracted directly from villi without further culture. The five exons of the G6Pase gene were amplified from genomic DNA, as previously described (Lei et al. 1993). Polymerase chain reaction (PCR) products were purified with a Qiaex 
Table 1. Summary of mutations in GSD Ia patients

\begin{tabular}{llllll}
\hline $\begin{array}{l}\text { Patient } \\
\text { no. }\end{array}$ & Sex & $\begin{array}{l}\text { Age (years) } \\
\text { at diagnosis }\end{array}$ & $\begin{array}{l}\text { R83H } \\
\text { mutation }\end{array}$ & $\begin{array}{l}727 \mathrm{G} \rightarrow \mathrm{T} \\
\text { mutation }\end{array}$ & $\begin{array}{l}\text { Other } \\
\text { mutations }\end{array}$ \\
\hline 1 & $\mathrm{~F}$ & 12 & + & + & \\
2 & $\mathrm{~F}$ & 4 & - & + & \\
3 & $\mathrm{M}$ & 3 & - & ++ & \\
4 & $\mathrm{M}$ & 2 & - & + & $793 \mathrm{G} \rightarrow \mathrm{T}$ \\
5 & $\mathrm{M}$ & 3 & - & + & \\
6 & $\mathrm{M}$ & 1 & + & + & \\
7 & $\mathrm{M}$ & 3 & + & + & \\
8 & $\mathrm{M}$ & 6 & + & + & \\
9 & $\mathrm{~F}$ & 1 & + & - & \\
10 & $\mathrm{M}$ & $8 / 12$ & + & + & \\
11 & $\mathrm{~F}$ & 1 & - & ++ & \\
12 & $\mathrm{M}$ & $4 / 12$ & + & - & \\
13 & $\mathrm{M}$ & $5 / 12$ & + & - & \\
14 & $\mathrm{M}$ & $7 / 12$ & - & ++ & \\
15 & $\mathrm{M}$ & 2 & ++ & - & \\
16 & $\mathrm{~F}$ & 2 & + & + & \\
17 & $\mathrm{M}$ & $5 / 12$ & + & - & 933insAA \\
18 & $\mathrm{~F}$ & 2 & + & + & \\
\hline
\end{tabular}

GSD, Glycogen storage disease; + , one positive allele; ++ , two positive alleles; - , negative

Gel Extraction kit (Qiagen, Hilden, Germany) and sequenced either directly or after cloning by $\left[\alpha^{35} \mathrm{~S}\right]$-dATP incorporation with a CircumVent sequencing kit (BioLabs, Hestfordshire, England, UK).

The $\mathrm{R} 83 \mathrm{H}$ and $727 \mathrm{G} \rightarrow \mathrm{T}$ mutations were also checked by restriction fragment length polymorphism (RFLP). $\mathrm{R} 83 \mathrm{H}$ creates a new Fok I restriction site, so that the exon 2 PCR product (191 bp) can be cut into 131-bp and 60-bp fragments (Lam et al. 1998). The $727 \mathrm{G} \rightarrow \mathrm{T}$ mutation destroys an amplification-created $B s r$ GI site, and thus prevents the cleavage of an 89-bp PCR product into 59-bp and 30-bp fragments (Okubo et al. 1997). Both the Fok I and $B s r$ GI enzymes were purchased from BioLabs.

\section{Results and discussion}

Thirty-two mutations were found in 36 GSD Ia chromosomes: 16 were $727 \mathrm{G} \rightarrow \mathrm{T}(44.44 \%) ; 13$ were $\mathrm{R} 83 \mathrm{H}$ (36.11\%); 1 was 341delG; 1 was 933insAA; and 1 was 793 $\mathrm{G} \rightarrow \mathrm{T}$ (Table 1). The 933insAA is a novel frame-shift mutation, and the polypeptide stops 16 amino acids after lysine 285. The patient is heterozygous for this mutation (data not shown). The $793 \mathrm{G} \rightarrow \mathrm{T}$ is a silent mutation which changes codon 238 from CTG to CTT (both CTG and CTT encoding leucine). The three other mutations have been described previously (Foster et al. 1997; Lam et al. 1998). The $727 \mathrm{G} \rightarrow \mathrm{T}$ and $\mathrm{R} 83 \mathrm{H}$ mutations together accounted for $80.56 \%$ of the GSD Ia chromosomes (29/36). In $66.67 \%$ of the patients (12/18), the mutations of both chromosomes could be identified by screening for these two mutations. These screening methods are, therefore, very helpful in the diagnosis and counseling of GSD Ia patients. Mutations in 5 of the 36 chromosomes were not found. They could be located in either the promoter or intronic regions.
Patient 13 is a compound heterozygote, in that he inherited the $\mathrm{R} 83 \mathrm{H}$ mutation from his father, and the $341 \mathrm{delG}$ mutation from his mother. His mother had a second pregnancy, and analysis of DNA from the villi of the fetus, both by RFLP and by direct sequencing, showed no R83H mutation (data not shown). The presence of the 341 delG mutation could not be excluded, but the signal for the mutant allele in direct sequencing is weak. This may be caused by maternal DNA contamination. Nevertheless, the fetus was not affected by GSD Ia.

Although $727 \mathrm{G} \rightarrow \mathrm{T}$ is the most common mutation in both Taiwan and Hong Kong Chinese, $\mathrm{R} 83 \mathrm{H}$ was found in seven of the ten mutant chromosomes in a Chinese population in the United States (Lei et al. 1995). Because most of the populations in Hong Kong and Taiwan come from the southeastern part of China, it is probable that the $727 \mathrm{G} \rightarrow \mathrm{T}$ mutation is more prevalent in Southeast China.

In Japan, the $727 \mathrm{G} \rightarrow \mathrm{T}$ mutation has been detected in 91\% of GSD Ia patients (Okubo et al. 1997; Kajihara et al. 1995). The genotype homogeneity in Japan is probably the result of a founder effect. The elemental Japanese population may have originated in both Southeast and Northeast Asia (Hanihara 1992; Horai et al. 1996). From the similarity in the G6Pase gene mutation between Taiwan and Japan, we hypothesize that the $727 \mathrm{G} \rightarrow \mathrm{T}$ mutation probably spread from Southeast Asia to Japan. This is analogous to findings with $\beta$-thalassemia, in that both the mutations and the associated haplotypes in the $\beta$-globin gene are identical in Chinese and Japanese (Naritomi et al. 1990). Future studies on the haplotypes of GSD Ia patients in these areas are required to prove this hypothesis.

Acknowledgments This work was supported in part by a Grant from the National Taiwan University (no. NTUH 85-163-A48).

\section{References}

Chen YT, Burchell A (1995) Glycogen storage disease. In: Scriver CR, Beaudet AL, Sly WS, Valle D (eds) The metabolic and molecular bases of inherited disease. McGraw-Hill, New York, pp 935-965

Chevalier-Porst F, Bozon D, Bonardot AM, Bruni N, Mithieux G, Mathieu M, Maire I (1996) Mutation analysis in 24 French patients with glycogen storage disease type 1a. J Med Genet 33:358-360

Foster JD, Pederson BA, Nordlie RC (1997) Glucose-6-phosphatase structure, regulation, and function: an update. Proc Soc Exp Biol Med 215:314-332

Hanihara K (1993) The population history of the Japanese. Nippon Ronen Igakki Zasshi 30:923-931

Horai S, Murayama K, Hayasaka K, Matubayashi S, Hattori Y, Fucharoen G, Harihara S, Park KS, Omoto K, Pan IH (1996) mtDNA polymorphism in East Asian populations, with special reference to the peopling of Japan. Am J Hum Genet 59:579-590

Hwu WL, Chuang SC, Tsai LP, Chang MH, Chuang SM, Wang TR (1995) Glucose 6-phosphatase gene G327A mutation is common in Chinese patients with glycogen storage disease type 1a. Hum Mol Genet 4:1095-1096

Hwu WL, Chiang SC, Huang SF, Chang MH, Wen WH, Wang TR (1999) Hypercalcemia in glycogen storage disease type Ia: a case with R83H and 341delG mutations. J Inher Metab Dis 22:937-938

Kajihara S, Matsuhashi S, Yamamoto K, Kido KM, Tsuji K, Tanae A, Fujiyama S, Itoh T, Tanigawa K, Uchida M, Setoguchi Y, Motomura M, Mizuta T, Sakai T (1995) Exon redefinition by a point mutation within exon 5 of the glucose-6-phosphatase gene is the major cause 
of glycogen storage disease type 1a in Japan. Am J Hum Genet 57:549-555

Lam CW, But WM, Shek CC, Tong SF, Chan YS, Choy KW, Tse WY, Pang CP, Hjelm NM (1998) Glucose-6-phosphatase gene (727G to T) splicing mutation is prevalent in Hong Kong Chinese patients with glycogen storage disease type 1a. Clin Genet 53:184-190

Lei KJ, Shelly LL, Pan CJ, Sidbury JB, Chou JY (1993) Mutations in the glucose-6-phosphatase gene that cause glycogen storage disease type 1a. Science 262:580-583

Lei KJ, Pan CJ, Shelly PL, Liu JL, Chou JY (1994) Identification of mutations in the gene for glucose-6-phosphatase, the enzyme deficient in glycogen storage disease type 1A. J Clin Invest 93:1994-1999
Lei KJ, Chen YT, Chen H, Wong LJC, Liu JL, McConkie-Rosell A, Van Hove JLK, Ou HCY, Yeh NJ, Pan LY, Chou JY (1995) Genetic basis of glycogen storage disease type 1a: prevalent mutations at the glucose-6-phosphatse locus. Am J Hum Genet 57:766-771

Naritomi Y, Nakashima H, Kagimoto M, Naito Y, Yokota E, Imamura $\mathrm{T}$ (1990) A common Chinese $\beta$-thalassemia mutation found in a Japanese family. Hum Genet 84:480-482

Okubo M, Yoshiko A, Kishimoto M, Shishiba Y, Murase T (1997) Identification of a point mutation (G727T) in the glucose-6phosphatase gene in Japanese patients with glycogen storage disease type 1a, and carrier screening in healthy volunteers. Clin Genet 51:179-183 